\title{
Double balloon enteroscopy: Bangladesh experience
}

\author{
Nath NC, Dhar SC, Uddin AFMH, Shil BC, Banik RK, Saha SK, Ali N \\ Department of Gastroenterology, Sir Salimullah Medical College and Mitford Hospital, Dhaka. \\ Email: nikhilnath65@yahoo.com
}

\begin{abstract}
Double balloon enteroscopy (DBE) is a newly developed endoscopic modality for diagnosis and treatment of small bowel disorders. The aim of this study was to evaluate the diagnostic and therapeutic impact of DBE in patient with suspected small bowel disease. This was a prospective study. Sixty one double balloon enteroscopy procedures (30 antegrade 31 retrograde) were done in thirty six patients(20M/16F, mean age 40 \pm 12.5 range 16-65 years ) at gastroenterology department, Sir Salimullah Medical College, Dhaka between October 2011 and September 2012. Indications for DBE included chronic abdominal pain 14(38.9\%), obscure GI bleeding 11(30.56\%), Small bowel obstruction $05(13.89 \%)$, and chronic diarrhea 06(16.67\%). The morphologic findings were ulcerations $13(36.11 \%)$, growth $03(8.33 \%)$, vascular ectasia $03(8.33 \%)$ and polyp $01(2.78 \%)$. Therapeutic interventions were performed in one patient only. No serious complications were observed. Diagnostic yields in case of chronic abdominal pain, chronic diarrhea, obscure GI bleeding and small bowel obstruction were $50 \%, 66 \%, 63 \%$ and $40 \%$ respectively. The findings were adenocarcinoma $04(11 \%)$, lymphoma 03(8.4\%), tuberculosis 03(8.4\%), non specific findings 05(13.9\%), IPSID 01(2.8\%), crohn's disease 01(2.8\%), vascular ectasia 03(8.33\%) and normal 16(44.44\%). DBE is well tolerated, feasible and useful technique for the diagnosis as well as treatment of small intestinal disorders.
\end{abstract}

\section{Introduction}

Due to length and anatomic position small bowel was hidden from direct visualization until a few years ago. Invention of new technology to evaluate small bowel disease is time demanding. Wireless capsule enteroscopy allows evaluation of the small bowel mucosa but it has no therapeutic interventional capacity ${ }^{\mathbf{1 , 2}}$. A novel method is the enteroscopy using double balloon ${ }^{\mathbf{3 , 4}}$. Double balloon enteroscopy developed by yamamoto et $\mathrm{al}^{\mathbf{5}}$. It has overcome the limitation of capsule enteroscopy. It allows full length inspection of the small bowel with therapeutic capabilities. However it requires considerable expertise and is significantly more invasive then capsule enteroscopy. Gastroenterology department in SSMC, Dhaka is the only government center in Bangladesh where this new technology is available. In this study our experience of Double balloon Enteroscopy in Bangladesh is presented.

\section{Materials and Methods}

All patients who underwent DBE at Gastroenterology department, Sir Salimullah Medical College between October, 2011 and September, 2012 were included in this study. Patients demographic data, Indication for the examination, result of previous non invasive small bowel imaging, investigation time and results of the procedure including findings, complications and pathologic report were recorded. The examination was performed using the $9.5 \mathrm{~mm}$ enterooscope Fujinon (Fujinon inc. Japan). The procedure was performed using the technique described by yamamoto et $\mathrm{al}^{5}$. Briefly the fujinon double balloon endoscopy system consist of a $200 \mathrm{~cm}$ endoscop, a $145 \mathrm{~cm}$ long overtube, and a pump. Two latex balloons are attached to the system one to the tip of the endoscope and the other to the overtube. The balloons are inflated and deflated using the pump. The examination begins with the overtube backloaded on the endoscape with both balloons collapsed. The endoscope is advanced into the bowel lumen until no further advancement is possible. The balloon on the tip of the endoscape is then inflated. This is followed by inserting the overtube into the lumen and inflating the overtube balloon. Using the overtube as an anchor. The balloon of the endoscope is deflated and the endoscape is advanced deeper into the small bowel. Then endoscope tip balloon is inflated to fix the intestine and the tube with the deflated balloon is slowly pushed forward over the enteroscope. Once the splinting tube reaches the endoscope tip, the tube balloon is inflated and the splinting tube and endoscope are withdrawn together. This maneuver leads to shortening of the gut, which is folded over the splinting tube, reducing intestinal looping. By 
repeating this process, the enteroscope is inserted into the deeper part of the intestine. Depth of insertion of the enteroscope was assessed by the method previously described for $\mathrm{DBE}^{\mathbf{6}}$. The length of the visualized small bowel was estimated by calculating the sum of each sequential progressive extensions of the scope through the over tube, starting the calculation from the duodenojejunal flexure onwards. The length of small bowel threaded during each maneuver was recorded with the individual lengths advanced being added up at the end of the examination. This technique has been evaluated in an animal model using DBE and the estimated intestimes depths, on average, showed only a deviation of less then $10 \%$ from the actual intestim depth ${ }^{6}$. No specific preparation is required for the oral approach. Patients were instructed to be nil orally for 8 hours before the procedures. For enteroscope through the anal approach bowel cleansing is required, as in colonoscopy. The examination is carried out with the patients under conscious sedition with propofol and fentanyl. Blood pressure, pulse rate, SPO2 (saturation of oxygen in arterial blood) were maintained during and after the procedure under the care of an experienced and trained physician. The approach (oral or anal) is determined by the endoscopist according to the assume location of the lesion, which was indication for the examination. The examination is terminated when the lesion is reached or when no further advancement is possible. If endoscopy through one route did not reach the lesion or if there was a specific clinical indications enteroscopy through both rote was performed. Fluoroscopy was used intermittently, especially when the insertion of the endoscope was difficult due to loop formation, intestinal adhesion. The patient position during enteroscopy was left lateral for the both route. All the procedure were carried out by experienced endoscopist. Two trained person assisted the endoscopist during procedure. All patients provided written consent prior to undergoing DBE.

\section{Results}

A total of 61 procedures were performed in 36 patients $(20 \mathrm{M} / 16 \mathrm{~F}$, mean age $40 \pm 12.5$ range $16-65$ years), twenty five patients underwent both the procedures, five patients underwent per oral rout and only six patients underwent anal rout. The clinical presentations and previous imaging or endoscopic findings are the indications of DBE to evaluate small bowel pathology. Indications included chronic abdominal pain 14(38.9\%), obscure GI bleeding (OGIB) 11 (30.56\%), chronic Diarrhoea 06(16.67\%), small bowel obstruction $05(13.89 \%)$ and abnormal imaging studies
10(27.78\%). All patients had undergone upper GI endoscopy and colonoscopy before DBE. Endoscopy and colonoscopy findings were normal. Barium follow through of small gut was done in selective patients. Nine patients showed abnormalities in small gut radiologically.

The range of depth of insertion was $60-360 \mathrm{~cm}$ beyond duodenojejunal flexure by the oral route and $40-280 \mathrm{~cm}$ proximal to the ileocaecal valve per anal route. The procedure duration for the first ten oral cases was $90 \pm 20$ minutes and for the remaining was $60 \pm 20$ minutes. Per anal route the procedure duration was $90 \pm 30$ minutes for the first ten cases and $80 \pm 20$ minutes for the remaining cases. Of the 61 procedures (36 patients), 27 procedures (20 patients) showed pathology. Nine patients underwent both the procedures and showed no pathology. Seven patients found pathology in both route. Endoscopic biopsies were required in 21 procedures. Polypectomy was done in one patient. The morphological findings were ulceration $13(36.11 \%)$, vascular ectasia $03(8.33 \%)$ Growth $03(8.33 \%)$ and polyp $01(2.78 \%)$. Table I shows that lesions were found in 7 of 11 patients (63\%) on DBE of obscure GI bleeding cases. Vascular Ectasia were found in three patients $(27.30 \%)$ and two patient $(18.18 \%)$ are small bowel tumour (SBT). One patients had ulcerated growth in the jejunum who presented with recurrent GI bleeding. The histology was suggestive of adenocarcinama. Another carcinoma was found in patient who had mucosal ulceration and nodularily in the jejunum. Two patients (18.18\%) with OGIB had non specific ulceration. A patient who had recurrent episodes of melena had a polyp in the distal jejunum which was removed with polypectomy snare. Diagnostic yield of DBE in chronic abdominal pain patients (table II) was 7 of $14(50 \%)$. Two patients had growth in the jejunum which were subsequently confirmed to be adenocarcinoma in one and lymphoma in the another. Five patients had jejunal and ileal ulceration. Among these; two patient (14.29\%) had circumferential ulceration with luminal narrowing. Caseating granuloma was found in histology of these two patients. Adenocarcinoma was found in one patient who had jejunal ulcer morphologically. Another had multiple diverticuli in jejunum with multiple ulceration in jejunum and ileum that showed non specific findings in histology. In chronic diarrhea diagnosis could be established in 04 of 06 subjects $(66 \%)$ (table III) One middle aged patient had multiple nodule in the jejunum and multiple ulcers with nodularity in ileum. Histologically IPSID was suspected. One patient $(16.67 \%)$ had multiple nodular swelling with suface ulceration in the jejunum that showed lymphoma in 
histology. Two patient were clinically suspected crohn's disease that showed non specific findings histologically. Morphologically one had multiple apthous ulceration with pseudopolyp in the jejunum and ileum suggestive of crohn's disease. Other one had multiple pearly nodule in the jejunum. Diagnosis could be established in 2 of $5(40 \%)$ in small bowel obstruction patients group (table IV). One young female had multiple jejunal ulcer and histologically showed non-hodgkin lymphoma. Another had multiple ulcers and nodular mucosa in the the jejunum and ileum that showed $\mathrm{TB}$ in histology. The pathologic findings are adenocarcinoma $04(11 \%)$, Lymphoma 03 (8.4\%), tuberculosis $03(8.4 \%)$, non specific findings 05
(13.9\%), vascular Ectasia 03(8.4\%), crohn's disease 01 (2.8\%) and normal 16 (44.45\%). Ileoceal intubations was not possible in three patient. Table VI shows that No enteroscopy associated severe complications such as perforations or bleeding were observed. Abdominal discomfort for few hours (05), intra mucosal hemorrhage (04) and sore throut (05) were observed. Enteroscopy could not be completed in one patient due to sudden fall of oxygen saturation. We can not claim panenteroscopy as India Ink tatto was not left as a landmark but we assume small gut location by obseving mucosal pattern and counting number of maneuvers.

Table 1: Diagnosis of OGIB patient after DBE

\begin{tabular}{|c|c|c|c|c|}
\hline $\begin{array}{c}\text { Number of patients } \\
(\mathrm{n})\end{array}$ & Diagnostic yield & $\begin{array}{c}\text { Vascular ectasia } \\
(\% \text { of the patient })\end{array}$ & $\begin{array}{c}\text { Non specific ulcer } \\
(\% \text { of the patient })\end{array}$ & $\begin{array}{c}\text { Malignancy after histopathology } \\
(\% \text { of the patient })\end{array}$ \\
\hline 11 & $63 \%$ & $3(27.30 \%)$ & $2(18.18 \%)$ & $2(18.18 \%)$ \\
\hline
\end{tabular}

Table II: Chronic abdominal pain in patient after DBE

\begin{tabular}{|c|c|c|c|c|c|}
\hline $\begin{array}{c}\text { Number of } \\
\text { patients(n) }\end{array}$ & Diagnostic yield & $\begin{array}{c}\text { Non specific ulcer } \\
(\% \text { of the patient })\end{array}$ & $\begin{array}{c}\text { Malignancy after histopathology } \\
(\% \text { of the patient })\end{array}$ & $\begin{array}{c}\text { Tuberculosis } \\
(\% \text { of the patient })\end{array}$ & $\begin{array}{c}\text { Lymphoma after histopathology } \\
(\% \text { of the patient })\end{array}$ \\
\hline 14 & $50 \%$ & $2(14.29 \%)$ & $2(14.29 \%)$ & $2(14.29 \%)$ & $1(7.14 \%)$ \\
\hline
\end{tabular}

Table III: Diagnosis of chronic diarrhoeal patient after DBE

\begin{tabular}{|c|c|c|c|c|c|}
\hline $\begin{array}{c}\text { Number of } \\
\text { patients }(\mathrm{n})\end{array}$ & $\begin{array}{c}\text { Diagnostic } \\
\text { yield }\end{array}$ & $\begin{array}{c}\text { Non specific ulcer } \\
(\% \text { of the patient })\end{array}$ & $\begin{array}{c}\text { Chron's disease } \\
(\% \text { of the patient })\end{array}$ & $\begin{array}{c}\text { Lymphoma after histopathology } \\
(\% \text { of the patient }\end{array}$ & $\begin{array}{c}\text { IPSID after histopathology } \\
(\% \text { of the patient }\end{array}$ \\
\hline 06 & $66 \%$ & $1(16.67 \%)$ & $1(16.67 \%)$ & $1(16.67 \%)$ & $1(16.67 \%)$ \\
\hline
\end{tabular}

Table IV: Diagnosis of small bowel obstruction patient after DBE

\begin{tabular}{|l|l|l|l|}
\hline Number of patients n) & Diagnostic yield & Tuberculosis (\% of the patient) & Lymphoma after histopathology(\% of the patient \\
\hline 05 & $40 \%$ & $1(20 \%)$ & $1(20 \%)$ \\
\hline
\end{tabular}

Table V: Evaluats complications of DBE

\begin{tabular}{|c|c|c|}
\hline Number of procedures(n) & $\begin{array}{c}\text { Major complications (\% perforation, } \\
\text { bleeding and pancreatitis) }\end{array}$ & $\begin{array}{c}\text { Minor complications (\%abdominal pain,intramucosal } \\
\text { bleeding and sore throat) }\end{array}$ \\
\hline 61 & $\mathrm{O} \%$ & $14(22.95 \%)$ \\
\hline
\end{tabular}

Table VI: Small bowel tumour(SBT), lymphoma, crohn's disease and tuberculosis by means of DBE

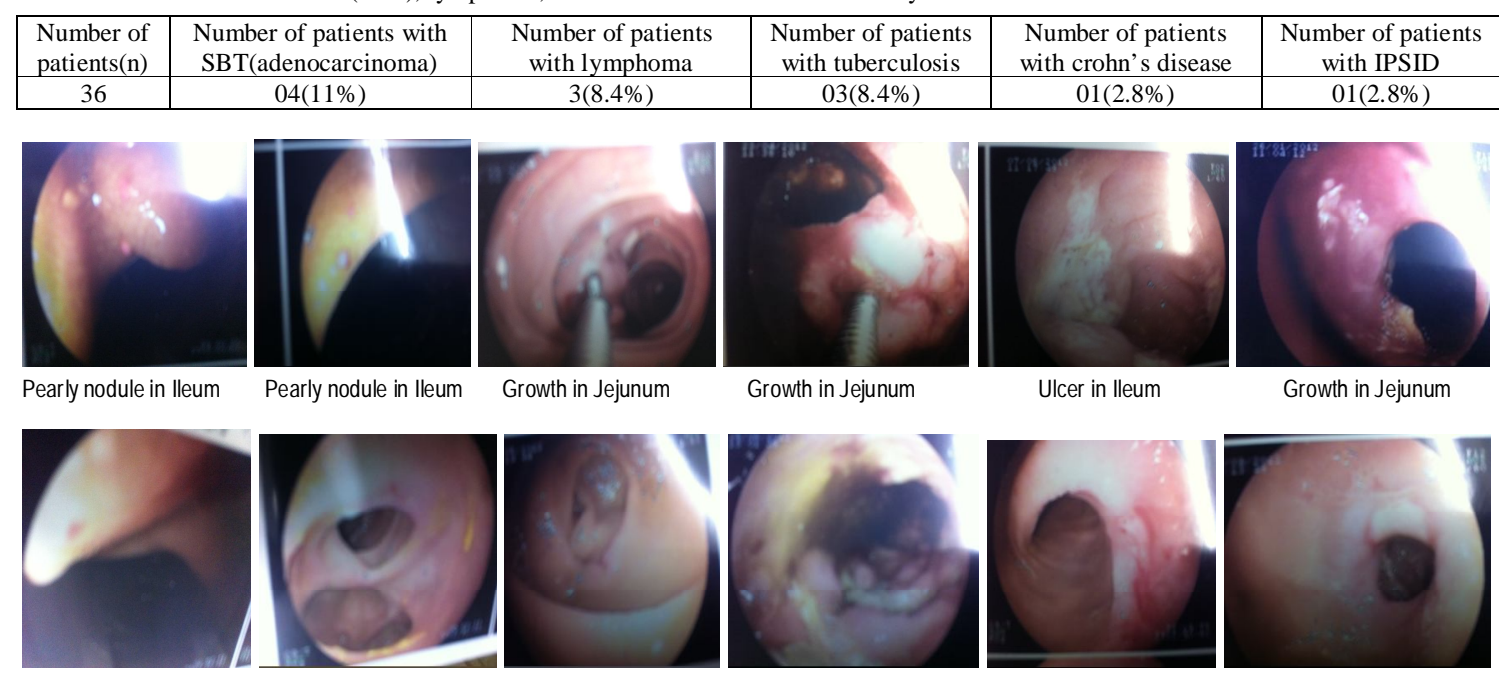

Vascular ectasia in small gut Diverticulem in Jejunum Vascular ectasia in small gut Ulcer, pseudopolyp in lleum

Ulcer in Jejunum

Ulcer, narrowing in lleum

Fig 1: Morphological pattern of small gut pathology. 


\section{Discussion}

Diagnosis and management of small bowel disorders is difficult. This is due to lack of availability of proper investigational modalities to visualize long small bowel loops. Balloon assisted enteroscopy is an emerging technique to carry out enteroscopies with therapeutic potential. As there is unavailability of capsule enteroscopy in Bangladesh a suitable endoscopic method is required for diagnosis and treatment of small gut disorders. There were four major indications for DBE in this studies. The diagnostic yields in patients with chronic abdominal pain, chronic diarrhoea, obscure GI bleeding and small gut obstruction were 50\%, $66 \%, 63 \%$ \& $40 \%$ respectively which is comparable to the study by Mohan Ramchandahi et $\mathrm{al}^{7}$. In patient with abdominal pain the enteroscopies were done to confirm the abnormalities seen in imaging. None of the patient had confirmed diagnosis before enteroscopy. Most of the patient had radiological findings. The yield of enteroscopies increases when there is abnormal radiological findings ${ }^{8}$. Emanuele Rondonotti et al found the diagnostic yield of OGIB patients is $75 \%^{9}$. Three meta-analysis confirmed a diagnostic yield of DBE of approximately $60 \%$ in OGIB patients ${ }^{10-12}$. Diagnostic yield of OGIB patient of this study is also comparable with other published studies (60$80 \%$ ) evaluating the role of DBE in various small bowel disease ${ }^{13-15}$. Enteroscopy yielded a diagnosis of patient with chronic diarrhea that is consistent with other published studies ${ }^{\mathbf{1 4}}$. Adi lahet MD et $\mathrm{al}^{\mathbf{1 6}}$ found polyp (14\%), Tumarrs (7\%), Vascular lesion (17.6\%), Inflammation (13\%), and normal (52\%) in his study. In our present study the pathologic findings are consistent with above studies. Almeida et al did DBE 78 patients and they got SBT (small bowel tumour) in 9 patients $(11.5 \%)$ and $55 \%$ of these SBT patient presented with $\mathrm{OGIB}^{17}$. In our study SBT is $11 \%$ and $18.18 \%$ of SBT patients presented with OGIB. Gerson et al showed $0.6 \%$ major complication rate for diagnostic DBE and $0.5 \%$ in therapeutic $\mathrm{DBE}^{\mathbf{1 8}}$. Mensink et al found $0.8 \%$ major complication rate for diagnostic DBE and $4.3 \%$ in therapeutic $\mathrm{DBE}^{\mathbf{1 9}}$. In our study there are minor complications only. No major complication occurred in our study subjects because we did diagnostic DBE in most of the patients. We did therapeutic DBE in only one patient. In conclusion, double balloon eneroscopy is a well tolerated safe procedure and it has a good diagnostic and therapeutic yield in small bowel disorders.

\section{References}

1. Swain p. Wireless capsule endoscopy. Gut 2003; 52: iv48-50.

2. Fireman Z, Kopelman Y. Small bowel capsule endoscopy: have we conquered the last frontier; Isr med Assoc J 2008; 10: 298-301.
3. Iddan G, Meron G, Gluknovsky A et al, wireless capsule endoscopy, Nature 2000; 405:417.

4. May A. Current status of double balloon enteroscopy with focus on the Wiesbaden results, Gastrointest. Endosc. 2007; 66:512-14.

5. Yamamoto H, Sekinc $\mathrm{Y}$, Sato $\mathrm{Y}$, et al. Total enteroscopy with a non surgical steerable double balloon method. Gastrointest Endosc. 2001; 53:216-20.

6. May A, Nachbar L, Schneider M et al. push and pull enteroscopy using the double balloon technique method of assessing depth of insertion and training of the enteroscopy technique using the Erlangen endo Trainer. Endocopy 2005; 37:66-70.

7. Ramchandani M , Reddy N, Gupta R etal . Diagnostic yield and therapeutic impact of single balloon enteroscopy: series of 100 cases. Journal of Gastroenterology and Hepatology. 2009; 1-8.

8. Gomez Rodriguez BJ, Ortiz Moyanol, Romeru Castro $\mathrm{R}$ et al, Diagnostic yield of 335 push videoenteroscopics Rev. Esp Enterm Diag. 2006; 98:82-92.

9. Emanuele R, Keijiro S, Tomonori $\mathrm{Y}$ et al. Doubleballoon endoscopy in clinical practice: Where are we now? Digestive Endoscopy.2012; 24: 209-219.

10. Pasha S, Leiighton J, Das A et al..Double-balloon enteroscopy and capsule endoscopy have comparable diagnostic yield in small bowel disease: A meta analysis. Clin Gastroenterol. Hepatol. 2008; 6:671-6.

11. Chen X, Ran Z-H,Tong J-L.Ameta analysis cof the yield of capsule endoscopy compared to doubleballoon enteroscopy in patients with small bowel disease.World J.Gastroenterol.2007; 13: 4372-8.

12. Teshima CW,Kuipers EJ,Van ZantenSVET AL.Double balloon enteroscopy and capsul endoscopy for obscure gastrointestinal bleeding:An updated meta-analysis. J. Gastroenterology 2004; 126:643-53.

13. Sun B, Rajan E, Cheng S et al. Diagnostic yield and therapeutic impact of double-balloon endoscopy for the diagnosis and treatment of small intestinal disease. Clin. GastroenterOl Hepatol. 2004; 2:1010-16.

14. Yamamoto H, Kita H, Sunada K, et al. Clinical Outcomes of double-balloon endoscopy for the diagnosis and treatment of small intestinal disease. Clin. Gastroenterol. Hepatol. 2004; 2:1010-16.

15. May A, Nachbar L. Double-balloon enteroscopy (pushand-pull enteroscopy) of the small bowel: feasibility of diagnostic and therapeutic yield in patients with suspected small bowel disease. Gastrointest. Endos. 2005; 62:62-70.

16. Lahat A, Nadler M, Simon C et al, Double Balloon Enteroscopy: a 2 year experience, IMAJ 2009; 11:456459.

17. Almeida N, Figuereido P, Lopes $S$ et al. Doubleballoon enteroscopy and small bobel tumours: A south European single-centre experience. Dig.dis. Sci. 2009; 54:1520-4.

18. Gerson LB,Toker J,Chiorean M ET AL.Complications associated double ballon enteroscopy at nine US centers.Clin. Gastroenterol.Hepatol.2009; 7:1177-82.

19. Mensink PB, Haringsma J,Kucharzik T, et al Complications of double balloon enteroscopy: Amulticenter survey. Endoscopy 2007; 39:613-5. 